\title{
Sleep and Lifestyle Habits of Osteopathic Emergency Medicine Residents During Training
}

Kate E. Hughes, DO; Patrick G. Hughes, DO; Mary J. Hughes, DO

From the Department of Emergency Medicine at the University of Arizona in Tucson (Dr K.E. Hughes); the

Sparrow Health System/

Michigan State University (MSU) Emergency Medicine

Residency in Lansing (Dr M.J. Hughes); the MSU

College of Osteopathic Medicine in Lansing (Drs K.E.

Hughes, P.G. Hughes, and M.J. Hughes); and the Florida Atlantic University Charles

E. Schmidt College of Medicine in Boca Raton, Florida (Dr P.G. Hughes). Dr K.E. Hughes was chief resident at MSU Emergency Medicine Residency at the time of manuscript submission.

Financial Disclosures: None reported.

Support: None reported.

Address correspondence to Kate E. Hughes, DO, Chief Resident, Michigan State

University Emergency Medicine Residency, Michigan State University College of Osteopathic Medicine, Department of Osteopathic Medical Specialties, 909 Fee Rd, East Lansing, Ml 48824-

6410.

Email: hughesk18@gmail.com Submitted May 16,2017 ; final revision received October 20, 2017; accepted November 14, 2017
Context: Duty hours were enacted in 2003 with the intent to improve patient safety and resident well-being. However, limited data exist regarding improvements in residents' well-being since the implementation of these restrictions.

Objective: To examine osteopathic emergency medicine (EM) resident characteristics regarding sleep and lifestyle habits and duty hour reporting.

Method: A convenience sample of osteopathic EM residents was surveyed at a statewide conference in May 2014. The conference included 177 residents from 15 osteopathic EM residencies. Data regarding demographics, sleep and lifestyle habits (including work-related motor vehicle incidents [MVIs] and chemical aid use for sleep/wakefulness), and duty hour reporting were collected. The Epworth Sleepiness Scale (ESS) score was calculated, with a score greater than 10 indicating sleep disturbance.

Results: Of the 128 residents (72\%) who returned the survey, approximately twothirds were female, were currently on an EM rotation, and were training in suburban emergency departments with more than 60,000 annual visits. Only $35 \%$ of respondents slept 8 or more hours per night during an EM rotation, and 63\% admitted to weight change during residency. Forty-two percent of respondents had a workrelated MVI, which was more likely to occur if their ESS score was greater than 11 $(P<.03)$. Mean (SD) ESS score was 9.9 (4.8; range, 0-24). Respondents reported using chemical aids for staying awake or going to sleep on a mean (SD) of 6.9 (9.3) days per month (range, 0-30). The majority of respondents (84\%) reported strict duty hour enforcement policies, few (17\%) had ever been asked to falsify reports, and more than half (56\%) had ever voluntarily reported false hours.

Conclusion: Most residents surveyed slept fewer than 8 hours per night and had a weight change during EM residency training. The majority of residents used a chemical aid for sleep or wakefulness. Nearly half of residents surveyed met criteria for disordered sleep, which was associated with a higher occurrence of MVIs.

J Am Osteopath Assoc. 2018;118(8):e45-e50

doi:10.7556/jaoa.2018.113

Keywords: duty hours, emergency medicine, Epworth Sleepiness Scale, resident health

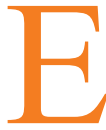
xcessive resident duty hours and inadequate sleep have been associated with reduced patient safety, increased medical errors, and increased resident fatigue. Because of these concerns, the Accreditation Council for Graduate Medical Education convened a task force in 2002 to establish duty hour limits and guidelines for all medical specialties, and these guidelines were further revised in $2011^{1,2}$ There were 3 
driving forces for these changes: (1) hospitalized patients were increasingly more ill, which placed increased demands on residents caring for them; (2) the public perceived that increased duty hours affected patient safety and resident well-being; and (3) if the medical profession did not impose duty hour limits, the government would. ${ }^{3}$

After the limitations were established, some studies reported benefits of duty hour limits. For example, limiting interns' hours was associated with fewer attentional failures in the intensive care unit and increased amount of sleep outside the hospital. ${ }^{4,5}$ However, Osborne and Parshuram ${ }^{6}$ called such findings into question and suggested that duty hour restriction alone does not consider workload as a source of resident fatigue. There may be other resident-associated factors that contribute to fatigue, including financial stress, circadian rhythm disruption with overnight shifts, and family obligations. A combination of these factors may play a larger role in resident fatigue than duty hours.

Although residents' improved sleep habits are often touted as a benefit of restrictions, little is known on the health, sleep habits, and duty hour reporting of osteopathic residents. Thus, the purpose of this study was to examine self-reported sleep and lifestyle habits and duty hours of osteopathic emergency medicine (EM) residents. We hypothesized that despite duty hour policies, residents would have poor sleep and lifestyle habits during rotations.

\section{Methods}

During the 2013-2014 academic year, 265 osteopathic EM residents were in 15 programs throughout a statewide postgraduate training system. These residents gathered monthly for a 4-hour didactic education conference in a central location. This conference is typically attended by all residents except those on vacation or who had just completed an overnight shift. A 36-item paper survey was distributed to all osteopathic EM residents who attended the monthly didactic conference on May 21, 2014. For those EM residents who attended via distance education, the survey was mailed with a postage-paid return envelope. This study was determined exempt by the associated institutional review board.

The survey consisted of questions related to demographics, sleep and lifestyle habits, and duty hour reporting. It was designed by 3 emergency physicians (K.E.H., P.G.H, and M.J.H.) involved in graduate medical education. Demographics included age, gender, postgraduate year, clinical setting, patient volume, and shift schedule.

Questions regarding common healthy lifestyle characteristics were in accordance with the United States Department of Agriculture Dietary Guidelines, as well as recommendations from Reeves and Rafferty. ${ }^{7}$ Using motor vehicle incidents (MVIs) (including falling asleep without a crash) as markers of sleep deprivation, data were gathered to determine what percentage of residents had ever had an MVI. ${ }^{8}$ Residents were also asked to list the number of days per 4-week rotation in which they used a chemical aid (medication, alcohol, $>1$ energy drink per day, $>5$ cups of coffee per day) to stay awake or fall asleep. In addition, an Epworth Sleepiness Scale (ESS) score was calculated for each participant. The ESS is a questionnaire used to measure the likelihood of falling asleep based on responses to 8 scenarios on a scale of 0 ("would never doze off") to 3 ("high chance of dozing off"), with a total score range from 0 to 24 . Scores between 0 and 10 are clinically normal, while scores greater than 10 generally indicate a need for clinical intervention for disordered sleep and daytime sleepiness. ${ }^{9}$ The ESS has good internal and test-retest reliability and has shown moderate correlation with objective sleeppropensity tests. ${ }^{9}$

Regarding duty hours, residents were asked to report their compliance with duty hours and whether they had been asked to falsify their reports or had done so voluntarily.

Using SPSS Statistics (IBM) for analysis, simple frequencies were reported where appropriate, and comparative analyses were done using $\chi^{2}$ test for 
categorical data comparisons. $P$ values less than .05 were considered statistically significant. Incomplete surveys were included in the final analyses.

\section{Results}

Of the 177 residents attending the conference on the day of survey distribution, 128 residents (72\%) returned the survey. Of those respondents, $70 \%$ were women (Table 1). First-year residents were more likely than others to report 180 to 200 scheduled hours per

Table 1.

Demographics of Osteopathic Emergency

Medicine Resident Survey Respondents $(\mathbf{N}=128)$

\begin{tabular}{|c|c|}
\hline Eharacteristic & No. (\%) \\
\hline \multicolumn{2}{|l|}{ Gender $(n=122)$} \\
\hline Male & $37(30.3)$ \\
\hline Female & $85(69.7)$ \\
\hline \multicolumn{2}{|l|}{ Age, $y(n=128)$} \\
\hline $24-27$ & $20(15.6)$ \\
\hline $28-30$ & $57(44.5)$ \\
\hline $31-34$ & $35(27.3)$ \\
\hline$>34$ & $16(12.5)$ \\
\hline \multicolumn{2}{|c|}{ Postgraduate Year $(n=128)$} \\
\hline 1 & $39(30.5)$ \\
\hline 2 & $30(23.4)$ \\
\hline 3 & $30(23.4)$ \\
\hline 4 & $29(22.7)$ \\
\hline \multicolumn{2}{|c|}{ Training Site Setting $(n=128)$} \\
\hline Rural/Suburban & $81(63.3)$ \\
\hline Urban/community & $42(32.8)$ \\
\hline Major city & $5(3.9)$ \\
\hline \multicolumn{2}{|c|}{ Training Site Annual Patient Volume $(n=126)$} \\
\hline $25,000-40,000$ & $21(16.7)$ \\
\hline $40,000-60,0000$ & $24(19.0)$ \\
\hline $60,000-75,0000$ & $57(45.2)$ \\
\hline$>75,000$ & $24(19.0)$ \\
\hline
\end{tabular}

4-week rotation $(P<.05)$. Among 126 respondents, 79 $(63 \%)$ were scheduled for 160 to 180 hours of clinical time per 4-week EM rotation, and 73 (57\%) had forward rotation shift scheduling (shifts moving from days to afternoons to overnights, in accordance with the circadian rhythm) during their EM rotation.

Lifestyle habits were poor, with 54 respondents (44\%) not consuming at least 3 servings of fruits or vegetables per day, 47 (41\%) exercising at least 4 days per week on EM rotation (and fewer on other rotations), and 77 (63\%) reporting a weight change (Table 2). Self-reported number of days with 8 hours of sleep per night varied by rotation. Only $17 \%$ of residents (19 of 114 ) reported getting 8 hours of sleep per night on intensive care unit, $17 \%$ (16 of 96) on trauma and surgery, and 35\% (42 of 120) on EM rotations. However, 91\% of residents (108 of 119) reported getting 8 or more hours of sleep per night on vacation. Mean (SD) ESS score was 9.9 (4.8; range 0-24). A score of 11 or higher was calculated for 53 of 127 respondents (42\%), and these respondents (29 of 53 [56\%]) were more likely to report an MVI than those with an ESS score of 10 or lower (23 of 70 [33\%]) $(P<.03)$. Respondents reported using chemical aids for staying awake or going to sleep on a mean (SD) of 6.9 (9.3) days per 4-week rotation (range, 0-30). Twelve (10\%) reported using a chemical aid daily.

Ninety respondents (70\%) reported being able to leave within 1 hour of their scheduled shift end. Of 99 respondents $(77 \%)$ who answered the duty hour questions, 83 $(84 \%)$ reported that their program had a policy of strict duty hour enforcement. In response to the question "Have you ever been asked to record other than the hours you actually worked to avoid a violation in duty hours?" 17 respondents (17\%) answered yes. In response to the question "Have you ever voluntarily recorded other than the hours you actually worked to avoid a violation in duty hours?" 55 (56\%) answered yes.

\section{Discussion}

The present study found that $63 \%$ of respondents had a weight change during residency. This finding highlights 
Table 2.

Sleep and Lifestyle Habits Reported by Osteopathic Emergency Medicine Residents (N=128)

\begin{tabular}{lc}
\begin{tabular}{l} 
Survey Item \\
\hline $\begin{array}{l}\text { Eat 3+ servings of fruits/vegetables daily } \\
(\mathbf{n}=\mathbf{1 2 2})\end{array}$
\end{tabular} & $\begin{array}{c}\text { Responses, } \\
\text { No. }(\%)\end{array}$ \\
\hline Yes & $68(55.7)$ \\
\hline No & $50(41.0)$ \\
\hline Didn't do that before residency & $4(3.3)$ \\
\hline Exercise $\geq \mathbf{4}$ d/wk per rotation & $73(64.6)$ \\
\hline Vacation ( $\mathrm{n}=113)$ & $47(41.2)$ \\
\hline Emergency medicine ( $\mathrm{n}=114)$ & $26(23.9)$ \\
\hline Intensive care unit $(\mathrm{n}=109)$ & $19(20.2)$ \\
\hline Trauma surgery $(\mathrm{n}=94)$ & \\
\hline Weight change during residency $(\mathrm{n}=\mathbf{1 2 2})$ & $54(44.3)$ \\
\hline Gain & $45(36.9)$ \\
\hline No change & $23(18.9)$ \\
\hline Loss
\end{tabular}

Percentage of time able to leave within 1 hour of scheduled shift end $(n=128)$

\begin{tabular}{ll}
\hline $0 \%-25 \%$ & $48(37.5)$ \\
\hline $26 \%-50 \%$ & $42(32.8)$ \\
\hline $51 \%-75 \%$ & $24(18.8)$ \\
\hline$>75 \%$ & $14(10.9)$ \\
\hline
\end{tabular}

Frequency of chemical aid ${ }^{a}$ for sleep/ wakefulness, d per 4-wk rotation $(n=124)$

\begin{tabular}{lc}
\hline Never & $36(29.0)$ \\
\hline $1-5$ & $46(37.1)$ \\
\hline $6-10$ & $20(16.1)$ \\
\hline $11-15$ & $2(1.6)$ \\
\hline $16-20$ & $5(4.0)$ \\
\hline $21-25$ & $3(2.4)$ \\
\hline Daily & $12(9.7)$ \\
\hline
\end{tabular}

Motor vehicle incident ${ }^{\mathrm{b}}$ while driving home from shift $(n=123)$

\begin{tabular}{cc}
\hline Yes & $52(42.3)$ \\
\hline No & $71(57.7)$ \\
\hline
\end{tabular}

(continued)

\section{Table 2 (continued). \\ Sleep and Lifestyle Habits Reported by Osteopathic Emergency Medicine Residents ( $N=128)$}

\begin{tabular}{|c|c|c|}
\hline \multicolumn{2}{|c|}{ Survey Item } & $\begin{array}{c}\text { Responses, } \\
\text { No. (\%) }\end{array}$ \\
\hline \multicolumn{3}{|c|}{$\begin{array}{l}\text { Epworth Sleepiness Scale score } \\
(n=127)\end{array}$} \\
\hline & $0-5$ & $22(17.3)$ \\
\hline & $6-10$ & 52 (40.9) \\
\hline & $11-15$ & $34(26.8)$ \\
\hline & $15-24$ & $19(15.0)$ \\
\hline $\begin{array}{l}\mathrm{b} \\
\mathrm{c}\end{array}$ & \multicolumn{2}{|c|}{$\begin{array}{l}\text { The Epworth Sleepiness Scale is an } 8 \text {-item tool in which } \\
\text { respondents respond regarding the likeliness of falling asleep in } 8 \\
\text { situations, from } 0 \text { (would never doze off) to } 3 \text { (high chance of } \\
\text { dozing off), for a total possible score of } 0 \text { to } 24 \text {. Scores }>10 \\
\text { indicate sleep disturbance and potential need for clinical } \\
\text { intervention. }\end{array}$} \\
\hline
\end{tabular}

often poor lifestyle habits of residents, including lack of exercise and adequate nightly sleep, which may contribute to weight change during training. According to Papp et al, ${ }^{9}$ up to $95 \%$ of residents cite the intensity of residency, as well as fatigue and sleep loss, as detrimental effects on physical health and healthy habits. Long hours and varying shifts in medical training are associated with an increased incidence of obesity and metabolic disorders. ${ }^{10}$

Thirty-five percent of respondents reported they were able to get 8 hours of sleep per night on EM rotations, while $91 \%$ reported at least 8 hours of sleep per night during vacation, suggesting that they prefer 8 hours of sleep per night. Fatigue due to sleep loss has a significant impact on a resident's ability to perform his or her duties and contributes to medical errors. ${ }^{9}$ The majority of residents cited sleep loss and fatigue as having had a major impact on their personal lives during residency, forcing them to postpone or defer many personal and social activities. ${ }^{9}$ Residents have 
also cited sleep loss and fatigue as deleterious to their ability to learn, in both the short and long term and in both formal and informal settings. ${ }^{9}$

Regarding the ESS score, $42 \%$ of respondents scored in a range in which clinical intervention is recommended. This percentage is smaller than what was reported by Papp et $\mathrm{al}^{9}$ in a 2004 study. This finding may result from the nature of EM vs other specialties, with fewer or shorter duration shifts scheduled per month. In their multi-institutional mixed-methods study using focus groups of residents, Papp et $\mathrm{al}^{9}$ concluded that regardless of training institution, specialty, stage of training, age, gender, marital status, or presence of children, feelings of sleepiness were consistent across the majority of residents.

Residents with an ESS score of 11 or more had more MVIs than did those with an ESS score from 0-10 $(P<.03)$. According to West et $\mathrm{al}^{8}{ }^{8}$ for each 1-point increase in ESS score, there is an associated $12 \%$ increase in the odds of reporting an MVI in the subsequent 3 months. Multiple studies ${ }^{8,9,11}$ have observed an association between resident fatigue and sleepiness with MVIs; this finding is significant, as it affects not only resident safety, but also the safety of the general public if the MVI involves another vehicle or pedestrian. It is also pertinent due to legal implications of vehicular homicide, with some states, such as New Jersey, defining reckless driving as driving "after having been without sleep for a period in excess of 24 consecutive hours." 12

For the purposes of this survey, chemical aids were defined as more than any illicit or prescribed medication, alcohol, more than 1 energy drink, or more than 5 cups of coffee per day. The majority of respondents (71\%) reported using chemical aids on at least 1 day during a rotation, and $10 \%$ reported using chemical aids daily. Handel et $\mathrm{al}^{13}$ cited rates of $46 \%$ for regular use of medications or alcohol as a sleep aid and $83 \%$ for use of stimulants for wakefulness, with the majority being caffeine based. Our finding illuminates the continued use of aids for sleep or wakefulness despite duty hour restrictions.
A minority of respondents (17\%) reported having ever been asked to falsify their duty hour reports, and more than half (56\%) reported having ever voluntarily falsified their duty hour reports. This finding is consistent with previous studies on duty hour compliance at residency programs across the country. For example, Blitz et al ${ }^{14}$ found that $32 \%$ of residents altered duty hour reports and $31.6 \%$ reported being pressured to alter their reports. Additionally, Carpenter et al ${ }^{15}$ found that $48 \%$ of residents admitted to underreporting their duty hour violations. The pervasiveness of noncompliance with duty hour reporting throughout many programs highlights that although duty hour restrictions are in place, residents do not report constant compliance with these restrictions.

This study has several limitations. Although it was conducted across a statewide system for osteopathic EM residents, the survey was distributed on only 1 day and therefore did not capture all possible residents who were in training in the 2013-2014 academic year. The survey data were self-reported without the ability to verify the answers due to anonymity. Programs were intentionally not identified in hopes of allowing more truthful reporting. The majority of participants admitted to dishonest reporting of duty hours, which may be due to the anonymous nature of this survey. Data cannot be corroborated from this self-reported survey; however, duty hours are self-reported by residents to their training institutions. Questions regarding enforcement of duty hour policy, dishonesty on duty hour reporting, and typical number of EM hours worked per 4-week rotation were not answered by 29 residents (23\%) who returned surveys. The absent responses may have resulted from the layout of the survey, which was printed on both sides of the pages, or from fear of repercussions for honest reporting. In a survey-based study, bias may occur as a result of recall bias. The survey was not a validated tool, which limits the generalizability of the results.

Future research may further evaluate the extent and specifics of chemical aids used by trainees, compare lifestyle habits of resident physicians to attending physicians 
or the general populace, or administer a survey at multiple time points throughout training and evaluate differences through rotations or postgraduate years.

\section{Conclusion}

Most respondents slept fewer than 8 hours per night and experienced weight change during EM residency training. The majority of residents used a chemical aid for sleep or wakefulness. Nearly half of respondents met criteria for disordered sleep, with associated higher numbers of MVIs, despite duty hour limitations. This survey provides valuable insight into sleep and lifestyle habits during EM residency training and suggests that the health of residents should be a prominent concern for the profession and its training programs.

\section{Author Contributions}

All authors provided substantial contributions to conception and design, acquisition of data, or analysis and interpretation of data; all authors drafted the article or revised it critically for important intellectual content; all authors gave final approval of the version of the article to be published; and all authors agree to be accountable for all aspects of the work in ensuring that questions related to the accuracy or integrity of any part of the work are appropriately investigated and resolved.

\section{References}

1. Owens JA, Veasey SC, Rosen RC. Physician, heal thyself: sleep, fatigue, and medical education. Sleep. 2001;24(5):493-495.

2. ACGME Task Force on Quality Care and Professionalism. Philibert I, Amis S Jr, eds. The ACGME 2011 Duty Hour Standard: Enhancing Quality of Care, Supervision, and Resident Professional Development. Chicago, IL: Accreditation Council for Graduate Medical Education; 2011.
3. Philibert I, Friedmann P, Williams WT, ACGME Work Group on Resident Duty Hours. New requirements for resident duty hours. JAMA. 2002;288(9):1112-1114.

4. Lockley SW, Cronin JW, Evans EE, et al; Harvard Work Hours, Health and Safety Group. Effect of reducing interns' weekly work hours on sleep and attentional failures. N Engl J Med. 2004;351(18):1829-1837.

5. Landrigan CP, Rothschild JM, Cronin JW, et al. Effect of reducing interns' work hours on serious medical errors in intensive care units. N Engl J Med. 2004;351(18):1838-1848. doi:10.1056/NEJMoa041406

6. Osborne R, Parshuram CS. Delinking resident duty hours from patient safety [review]. BMC Medical Education. 2014;14(suppl 1):S2. doi:10.1186/1472-6920-14-S1-S2

7. Reeves MJ, Rafferty AP. Healthy lifestyle characteristics among adults in the United States, 2000. Arch Intern Med. 2005;165(8):854-857. doi:10.1001/archinte.165.8.854

8. West CP, Tan AD, Shanafelt TD. Association of resident fatigue and distress with occupational blood and body fluid exposures and motor vehicle incidents. Mayo Clin Proc. 2012;87(12):1138-1144. doi:10.1016/j.mayocp.2012.07.021

9. Papp KK, Stoller EP, Sage P, et al. The effects of sleep loss and fatigue on resident-physicians: a multi-institutional, mixed-method study. Acad Med. 2004;79(5):394-406.

10. Mota MC, Waterhouse J, De-Souza DA, et al. Sleep pattern is associated with adipokine levels and nutritional markers in resident physicians. Chronobiol Int. 2014;31(10):1130-138. doi:10.3109 /07420528.2014.957300

11. Barger LK, Cade BE, Ayas NT, et al; Harvard Work Hours, Health and Safety Group. Extended work shifts and the risk of motor vehicle crashes among interns. N Engl J Med. 2005;352(2):125-134.

12. Maggie's Law, Pub L c 143, §2C:11-5 (NJ 2003).

13. Handel DA, Raja A, Lindsell CJ. The use of sleep aids among emergency medicine residents: a web based survey. BMC Health Serv Res. 2006;6:136

14. Blitz JB, Rogers AE, Polmear MM, et al. Duty hour compliance: a survey of US military medical interns and residents. Mil Med. 2017;182 (11):1997-2004.

15. Carpenter RO, Spooner J, Arbogast PG, et al. Work hours restrictions as an ethical dilemma for residents: a descriptive survey of violation types and frequency. Curr Surg. 2006;63(6):448-55

(๑) 2018 American Osteopathic Association 